\title{
Correction to: Microbial Degradation of Hydrocarbons in the Ecosystem
}

\author{
Anupreet Kaur
}

\section{Correction to:}

Chapter 14 in: V. Kumar et al. (eds.), Microbial Action on Hydrocarbons, https://doi.org/10.1007/978-981-13-1840-5_14

Figure 14.1 of this chapter was inadvertently published with errors. The correct presentation is given here.

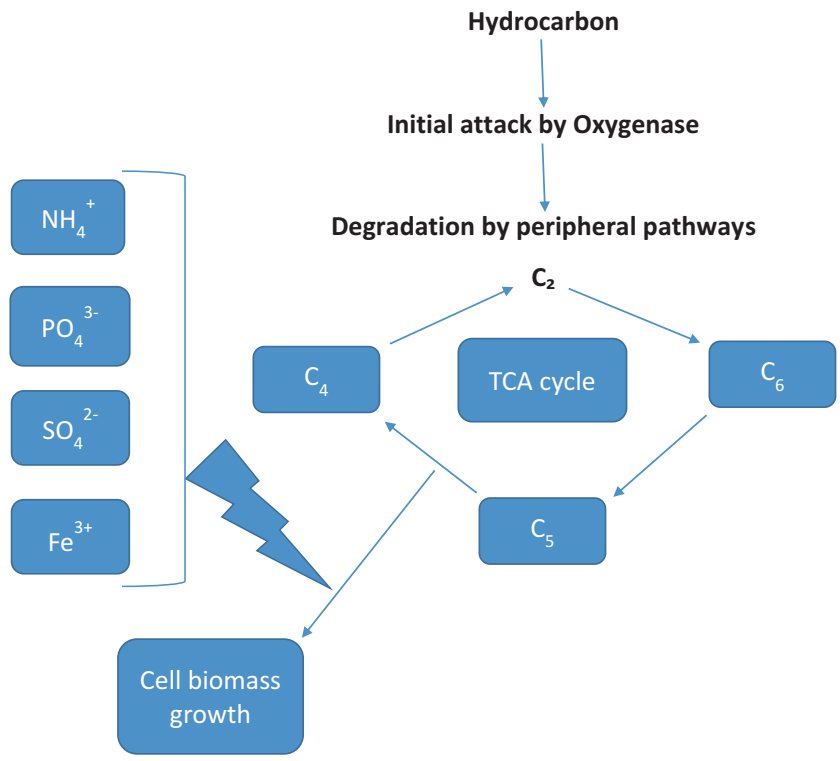

Fig. 14.1 Main principles of the aerobic degradation of hydrocarbons

The updated version of this chapter can be found at https://doi.org/10.1007/978-981-13-1840-5_14 